\title{
Wagnériens et wagnérisme
}

\section{Christophe Didier}

\section{(2) OpenEdition}

Journals

Édition électronique

URL : https://journals.openedition.org/rbnu/2297

DOI : $10.4000 /$ rbnu.2297

ISSN : 2679-6104

\section{Éditeur}

Bibliothèque nationale et universitaire de Strasbourg

\section{Édition imprimée}

Date de publication : 1 mai 2013

Pagination : 6-7

ISBN : 9782859230432

ISSN : 2109-2761

\section{Référence électronique}

Christophe Didier, «Wagnériens et wagnérisme », La Revue de la BNU [En ligne], 7 | 2013, mis en ligne le 01 mai 2013, consulté le 08 août 2021. URL : http://journals.openedition.org/rbnu/2297 ; DOI : https:// doi.org/10.4000/rbnu. 2297

\section{(C) $10(0$}

La Revue de la BNU est mise à disposition selon les termes de la Licence Creative Commons Attribution - Pas d'Utilisation Commerciale - Partage dans les Mêmes Conditions 4.0 International. 


\section{LE DOSSIER}

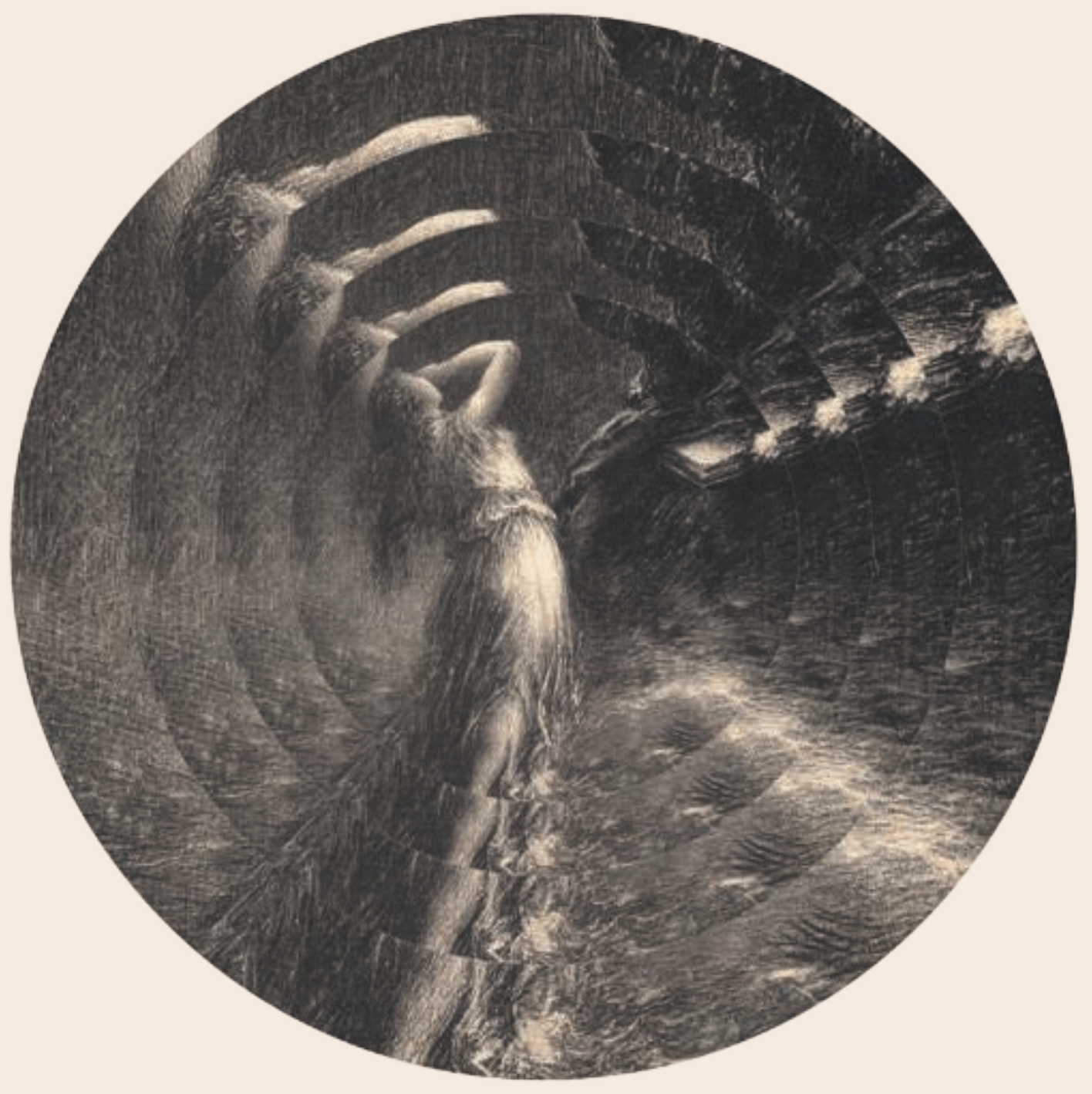




\section{Wagnériens et wagnérisme}

En 2012, Richard Wagner faisait son entrée à la Bibliothèque nationale et universitaire de Strasbourg par l'achat d'une collection privée, le fonds Boulet-Devraigne, composée de 1100 pièces environ et centrée sur la postérité que le musicien eut en France et la quasidévotion que lui vouent, depuis la fin $\mathrm{du} 19^{\mathrm{e}}$ siècle, les " pèlerins " de Bayreuth. Le compositeur rejoignait ainsi une ville qui était loin de lui être indifférente : visiteur enthousiaste, comme Goethe, de la cathédrale, il s'y rendit à plusieurs reprises et envisagea même, en 1858 puis en 1860, d'y faire représenter Tristan.

Mais à vrai dire, il n'était pas totalement absent des fonds de la bibliothèque, qui possédait déjà, entre autres, une page manuscrite - et dédicacée - reprenant les premières mesures du second acte de Parsifal. Elle avait été offerte par le compositeur à Arthur de Gobineau, probablement lors d'un séjour de ce dernier à Bayreuth en 1882. Toutefois, l'achat d'un ensemble patiemment constitué, et donc d'une grande cohérence dans ses lignes de force, donne une tout autre dimension à la présence de Wagner dans une ville et dans un lieu qui lui ont déjà rendu hommage, lors d'une exposition organisée par la BNU à l'occasion des cent ans du Festival de Bayreuth, en 1976.

En 2013, Wagner est partout, bicentenaire de sa naissance oblige. Sa ville natale de Leipzig en fait, plus que jamais, un argument de communication touristique ; Bayreuth se prépare à monter le " Ring du bicentenaire "; chaque maison d'opéra, en Allemagne comme ailleurs, tient à s'associer à la commémoration. On ne saurait pourtant parler de redécouverte, tant le compositeur continue d'enflammer les passions et de susciter les débats les plus contradictoires - où la musique n'a d'ailleurs pas toujours sa part. Comme on l'a souvent souligné, Wagner est devenu, au fil du temps, un phé- nomène tout autant social, historique et politique que musical. Il faut admettre comme telle la permanence de ce qu'on appelle le " wagnérisme ", que celui-ci s'attache à la musique, à la personnalité du musicien, à ses écrits ou aux interprétations que son œuvre a suscitées.

Quelle meilleure occasion que cette année 2013 (année aussi, rappelons-le, de commémoration des cinquante ans du Traité de l'Elysée) pour valoriser un fonds constitué par deux admirateurs français du musicien allemand ? Personnel par nature, donc unique en tant qu'ensemble, il nous introduit dans un siècle de wagnérisme et dans l'intimité des wagnériens, à travers la masse documentaire ainsi constituée, mais aussi grâce à des photographies, des lettres et des documents inédits. Il met en lumière le wagnérisme comme fait politique et social, singularité qui distingue le compositeur en lui donnant, souvent malgré lui, une dimension idéologique que n'eurent jamais d'autres géants comme Bach, Mozart ou même Beethoven.

Ce numéro de La Revue entend rendre compte de ces diverses facettes de l'auteur du Ring. Il montre, si besoin était, qu'une bibliothèque a toute sa place dans la commémoration d'un phénomène d'abord musical. C'est d'ailleurs ce qu'a bien compris la ville de Bayreuth, qui accueillera cet été dans sa médiathèque, pendant la durée du festival, une exposition constituée de pièces majeures du fonds. Intitulée Aus gallischer Sicht-Richard Wagner, vu de France et produite par le Cercle Richard Wagner de Strasbourg, elle montrera, sur le site même élu par le compositeur, le legs des deux collectionneurs à la postérité, image de l'influence que son œuvre exerça, et continue d'exercer sur les débats esthétiques contemporains.

\section{Christophe Didier}

